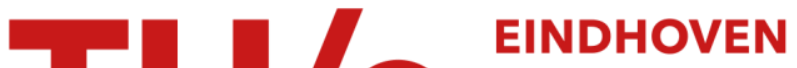 UNIVERSITY OF TECHNOLOGY
}

\section{A fundamental study of the effects of modifiers in supercritical fluid chromatography}

\section{Citation for published version (APA):}

Janssen, J. G. M., Schoenmakers, P. J., \& Cramers, C. A. M. G. (1989). A fundamental study of the effects of modifiers in supercritical fluid chromatography. Journal of High Resolution Chromatography, 12(10), 645-651. https://doi.org/10.1002/jhrc.1240121003

DOI:

10.1002/jhrc. 1240121003

Document status and date:

Published: 01/01/1989

\section{Document Version:}

Publisher's PDF, also known as Version of Record (includes final page, issue and volume numbers)

\section{Please check the document version of this publication:}

- A submitted manuscript is the version of the article upon submission and before peer-review. There can be important differences between the submitted version and the official published version of record. People interested in the research are advised to contact the author for the final version of the publication, or visit the $\mathrm{DOI}$ to the publisher's website.

- The final author version and the galley proof are versions of the publication after peer review.

- The final published version features the final layout of the paper including the volume, issue and page numbers.

Link to publication

\section{General rights}

Copyright and moral rights for the publications made accessible in the public portal are retained by the authors and/or other copyright owners and it is a condition of accessing publications that users recognise and abide by the legal requirements associated with these rights.

- Users may download and print one copy of any publication from the public portal for the purpose of private study or research.

- You may not further distribute the material or use it for any profit-making activity or commercial gain

- You may freely distribute the URL identifying the publication in the public portal.

If the publication is distributed under the terms of Article 25fa of the Dutch Copyright Act, indicated by the "Taverne" license above, please follow below link for the End User Agreement:

www.tue.nl/taverne

Take down policy

If you believe that this document breaches copyright please contact us at:

openaccess@tue.nl

providing details and we will investigate your claim. 


\title{
A Fundamental Study of the Effects of Modifiers in Supercritical Fluid Chromatography
}

\author{
J. G. M. Janssen ${ }^{1 / 2)}$, P. J. Schoenmakers ${ }^{11}$, and C. A. Cramers ${ }^{\star 2)}$ \\ 1)Philips Research Laboratories, P.O. Box 80000, 5600 JA Eindhoven, The Netherlands \\ 2) University of Technology, P.O. Box 513,5600 MB Eindhoven, The Netherlands
}

\section{Key Words:}

Supercrittical fluid chromatography, SFC

Packed columns

Modifiers

Adsorption isotherms

Reaction model

\section{Presented at the \\ Tenth International Symposium on Capillary Chromatography}

\section{Summary}

The effects of organic modifiers on retention and peak shape in packed-column supercritical fluid chromatography were studied. The adsorption behavior of different modifiers was investigated on stationary phases consisting of hydrocarbon monolayers chemically bonded on silica. Adsorption isotherms for several modifiers were recorded using breakthrough measurements. The results were compared with those obtained by a simple method based on the injection of different sample sizes. Modifiers were selected to reflect various types of interactions with the silica support. Isotherms were found to be approximately Langmuirean. Experiments were performed to elucidate the influence of adsorbed molecules on the retention of selected test solutes.

The introduction of a solvent modifier can lead to a substantial change in the mobile phase density, the effect of which is comparable with that of an increase in the density of pure carbon dioxide. Our results confirm that the effects of low concentrations of modifiers (between 0 and 2 percent) in packed-column SFC are largely due to deactivation of residual silanol groups on the silica support. The accessibility of the active sites was found to depend strongly on the size and structure of the modifier molecules. The decrease of retention due to the addition of low concentrations of modifiers could be described accurately by a model derived from Langmuir adsorption behavior. Some semi-quantitative rules for the selection of modifiers and the required concentrations for optimum deactivation of the support are discussed.

\section{Introduction}

The elution of polar compounds in supercritical fluid chromatography (SFC) often requires the addition of polar solvents ("modifiers") to the mobile phase. The effects of modifiers on retention and selectivity in packed-column SFC have been the subject of a number of investigations (e.g. [1-5]). In these reports, the addition of small amounts of modifier $(<1 \%)$, was shown to drastically reduce the retention of polar solutes. In capillary SFC, however, much higher percentages were required to obtain significant changes in retention (e.g. [6-7]).

Retention in SFC is governed by the combination of the properties of both the mobile and the stationary phase. The addition of a modifier to the mobile phase can induce changes in the nature of either of these phases. Hence, the effect of adding a modifier to the supercritical mobile phase can be divided into a mobile-phase modification effect and a stationary-phase effect. For a fundamental understanding of the effects of modifiers in $\mathrm{SFC}$, it is of considerable importance to determine the relative influence of mobile-phase and stationary-phase effects. Mobile-phase properties liable to change upon the addition of modifiers to the supercritical fluid, include both the density, and the nature and extent of physicochemical interactions between the solute and the mixed mobile phase. For mixed mobile phases, a higher density is anticipated because the critical parameters of the mixed fluid are expected to be higher than those of $\mathrm{CO}_{2}$. The assumption of a changing nature of the interactions between the solute and the mobile phase upon the addition of a modifier to the carbon dioxide is supported by spectroscopic measurements of solvatochromic shifts [8].

As stated before, the addition of a modifier to the mobile phase may not exclusively affect the properties of the mobile phase, but may also have an impact on the stationary phase. The use of modifiers can lead to deactivation of adsorptive sites on the column wall or on the packing material $[2,4]$. Additional effects of modifiers on stationary-phase properties might include swelling or increased solvation of the stationary phase by the organic modifier $[7,9,10]$. The observation that small amounts of modifiers have a large influence on retention and peak shape in packed-column SFC, whereas similar amounts only have a minor influence in (highly deactivated) capillary columns, indicates that stationary-phase modification by the modifier is the predominant mechanism affecting retention in packedcolumn SFC. It is generally assumed that residual silanol groups on the surface of the packing material may be responsible for the poor peak shapes and excessive retention times often observed for polar solutes in packed-column SFC. If the active silanol sites are not properly deactivated, either directly by chemical "endcapping" reactions, or indirectly by modifying the mobile phase, a system remains where adsorption at these sites contributes to a mixed retention mechanism [11].

The extent to which silanol groups are deactivated by a modifier will be a function of the nature and the number of molecules adsorbing on the surface. The amount adsorbed can be described by an adsorption isotherm. Various types of adsorption isotherms have been used in the literature to describe adsorption 
systems in LC, GC, and SFC. For example, Scott and Kucera [12] derived a bilayer adsorption isotherm to describe adsorption of THF and 2-propanol on silica gel from $n$-heptane. Jönsson and Mathiasson [13] proposed a four-parameter adsorption isotherm to describe the influence of sample size on retention in packed-column GC. Lochmüller and Mink [14] observed Langmuirean adsorption behavior for the adsorption of ethyl acetate on "bare" silica from supercritical carbon dioxide. Several methods were described for measuring adsorption isotherms in chromatographic systems. Extensive discussions have been published by De Jong [15] and by Jacobson [16]. On the basis of accuracy, precision and speed, these authors found the breakthrough or frontal-analysis method to be the best.

In this paper we will describe the effects of modifiers on the mobile phase and the stationary phase properties. We will present adsorption isotherms for several modifiers on octadecyl-modified silica, obtained using the break-through method. The effect of the modifier concentration in the mobile phase on the stationary-phase coverage was established. The effects of low concentrations of both polar and non-polar modifiers on the retention behavior of selected test compounds were studied. A model will be presented to correlate adsorption behavior of the modifier and retention characteristics of the test solutes. This model is based on a mixed retention mechanism, according to which hydrocarbon chains and silanol groups contribute independently.

\section{Theory}

In this section we will derive a model for the retention of polar solutes in carbon-dioxide based SFC with low concentrations of modifiers and using packed columns with chemically bonded phases (CBP's). We assume that two mechanisms contribute independently to the overall retention. The first retention mechanism is the interaction of the solutes with the chemically bonded phase. The second mechanism is the adsorption of the solutes on active sites (silanol groups) on the surface of the packing material. The observed total capacity factor can then be expressed as:

$$
k_{\mathrm{obs}}=k_{\mathrm{CBP}}+k_{\mathrm{Sil}}
$$

where $k_{\text {obs }}$ is the observed capacity factor and $k_{\mathrm{CBP}}$ and $k_{\text {sil }}$ are the capacity factors for the interaction with the chemically bonded phase and for the adsorption on the silanols, respectively. The relative contribution of the silanol groups to the overall retention will depend on the number of surface silanols accessible for the solute molecules. If a modifier is added to the mobile phase, modifier molecules will compete with the solute for interaction with the surface of the packing material. Under suitable conditions, they will shield the silanols. Hence, the number of silanol groups contributing to the retention will decrease and, consequently, the last term in eq. (1) will decrease. We now assume that the influence of the modifier addition on the properties of the mobile phase is negligible. This assumption is believed not to be too severe, since low modifier concentrations have only a minor effect on retention in capillary SFC. Using this assumption, eq. (1) can be rewritten to account for the presence of modifiers:

$$
k_{\mathrm{obs}}\left(C_{\mathrm{m}}\right)=k_{\mathrm{CBP}}+k_{\mathrm{sil}}\left(C_{\mathrm{m}}\right)
$$

The addition of $c_{m}$ indicates the dependence of the parameter on the modifier concentration. We now assume that the contribution of the silanol groups to the overall retention is directly proportional to the number of accessible silanols, i.e. those silanols not chemically removed by CBP groups and not physically occupied by modifier molecules. We opted to use the Langmuir equation for describing the relative number of occupied sites. Despite possible criticism regarding the underlying assumptions, Langmuir adsorption isotherms generally provide a good description of experimental data (e.g. [14-16]). Here, we will use the Langmuir adsorption equation without assigning physical meaning to the parameters. The Langmuir adsorption equation reads:

$$
N_{\mathrm{S}}=\frac{C_{\mathrm{m}}}{a C_{\mathrm{m}}+b}
$$

Here $c_{m}$ is the concentration of modifier in the mobile phase and $N_{\mathrm{S}}$ is the number of modifier molecules adsorbed on the surface. a and $b$ are constants which can depend on the modifier, the stationary phase, the mobile phase, the temperature, and the pressure. These constants have to be determined experimentally. From eq. (3) it follows that at high modifier concentration:

$$
N_{S}^{\max }=1 / a \text {. }
$$

Here $N_{S}^{\max }$ is the maximum number of modifier molecules adsorbing on the surface. The fraction of occupied sites $(\Theta)$ can be expressed as:

$$
\Theta=\frac{N_{\mathrm{S}}}{N_{\mathrm{S}}^{\mathrm{max}}}=\frac{C_{\mathrm{m}}}{C_{\mathrm{m}}+d}
$$

where $d=b / a$. With the assumption that the retention caused by adsorption of the solutes on the silanol groups is proportional to the number of unoccupied silanol sites, we obtain:

$$
k_{\text {sil }}\left(c_{\mathrm{m}}\right)=k_{\mathrm{sil}}^{0}(1-\Theta
$$

Here $k_{\text {sil }}^{0}$ is the contribution of the silanol groups to the observed capacity factor at zero modifier concentration. Combination of eq. (2), (5), and (6) finally yields:

$$
k_{\mathrm{obs}}\left(c_{\mathrm{m}}\right)=k_{\mathrm{CBP}}+k_{\mathrm{sil}}^{0}\left[1-\frac{c_{\mathrm{m}}}{c_{\mathrm{m}}+d}\right]=k_{\mathrm{CBP}}+\frac{d k_{\mathrm{sil}}^{0}}{c_{\mathrm{m}}+d}
$$

\section{Experimental}

\subsection{Equipment and Materials}

All experiments were performed on a home-built SFC instru ment. A detailed description of the system has been published previously [17]. The mobile-phase delivery system consisted of two reciprocating-piston pumps to allow operation with mixed mobile phases. The ratio of the flow rates of the pumps was kept constant, whilst the total flow rate was controlled by a constantpressure feed-back circuit. The column $(150 \times 4.6 \mathrm{~mm})$ was

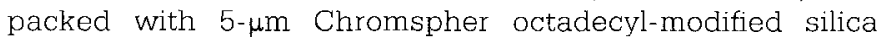
(Chrompack, Middelburg. The Netherlands). The column contained 1.75 grams of stationary phase. The specific surface area was $176 \mathrm{~m}^{2} / \mathrm{g}$ according to the manufacturer. The carbon dioxide (Philips Gasfabriek, Eindhoven, The Netherlands) had a purity of $99.8 \%$. The test solutes were phenol, phenanthrene, benzophenone, 2-hydroxyethyl methacrylate (2-HEMA), and 4-pentoxy-4'-cyano-biphenyl (M15). All modifiers (p.a. grade) were obtained from Merck (Darmstadt, FRG). To allow stable operation of the modifier pump at extremely low modifier con- 
centrations, the modifiers were dissolved in hexane in varying concentrations. The concentration of the hexane/modifier mixture relative to the carbon dioxide was always $5 \%(\mathrm{v} / \mathrm{v})$. Ail experiments were performed at $45^{\circ} \mathrm{C}$ at constantinlet and outlet pressures of 179 and 162 bar, respectively

\subsection{Procedures}

Estimation of the relative number of adsorbing molecules: Schoenmakers et al. [18] recently used a mixed-retention model to describe the influence of sample size on retention in packedcolumn SFC. Observed capacity factors were modelled as the independent contributions of (i) the interaction of the solute with the chemically bonded phase and (ii) the adsorption on active sites. With the assumption that adsorption of solute molecules on active sites on the surface can be described by a Langmuir-type equation, Schoenmakers arrived at an equation of the form:

$$
k=\frac{a^{\prime}}{b^{\prime}}+d^{\prime}
$$

In this equation $a^{\prime}, b^{\prime}$, and $d^{\prime}$ are constants and $Q_{i n j}$ is the injected amount of solute. The value of $a^{\prime} / b^{\prime}$ can be used as an indication of the relative number of accessible silanol groups on the stationary phase. The first term on the right-hand side represents the contribution of adsorption on residual silanols to retention, whereas the second term describes the CBP contribution to retention. If it is assumed that small, polar molecules, such as those commonly used as modifiers in SFC, are not retained by the CBP, the second term can be neglected. In this case the model yields after rewriting:

$$
1 / k=\alpha Q_{i n j}+\beta
$$

Where $\alpha$ and $\beta$ are constants. The constant $\alpha$ is inversely proportional to the maximum number of molecules that can be adsorbed on the surface. This model was used in the present study to obtain an indication of the relative number of adsorbing molecules for various modifiers. Graphs of $1 / k$ vs. $Q_{\text {inj }}$ were measured for a number of modifiers. Modifiers were injected as individual standards of varying concentration with either hexane or dichloromethane as the solvent.

Isotherm measurements: The breakthrough method was employed to quantify modifier coverage on the stationary phase as a function of the mobile-phase composition. A detailed discussion of this method has been published by Huber and Gerritse [19]. For the measurement of adsorption isotherms, a Rheodyne 7010 valve was incorporated between the injector and the chromatographic column to allow switching from pure $\mathrm{CO}_{2}$ to a mixed mobile phase (see Figure 1). At the start of a breakthrough experiment, the valve was in position $A$ and the column was equilibrated with neat carbon dioxide. After reaching equilibrium, the valve was switched to position $B$ so that the column was by-passed and shut off leak-tight. With the valve in this position, the pumps and the lines could be purged with the mixed mobile phase consisting of a hexane/modifier-carbon dioxide mixture. When a stable mobile phase composition was obtained, the valve was switched back to position A. The breakthrough profile could then be recorded. The column dead-time was assumed to correspond to the refractive index peak caused by the hexane. The hexane/modifier flow entering the system was measured using a burette. The concentration of modifier in

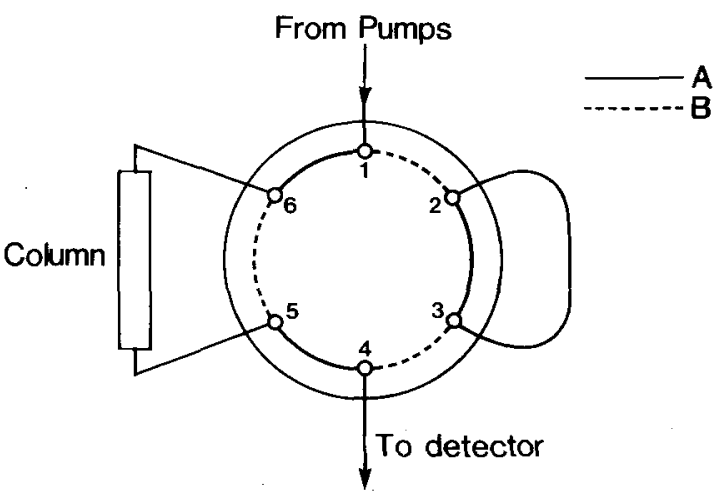

Figure 1

Switching valve for the breakthrough measurements. For discussion see text.

the mobile phase was calculated from the measured flow rate of modifier into the system and the total gaseous flow rate evolving from the reducing valve at the detector outlet. The concentration was expressed as moles of modifier relative to the total molar flow rate evolving from the system. The adsorbed amount was calculated from the net breakthrough time and the modifier flow entering the system. By simultaneously varying the modifier concentration in the hexane and the amount of hexane/modifier added to the carbon dioxide, it was verified that the concentration of hexane had no detectable influence on the adsorbed amount

Effects of modifier on retention: Retention times of the selected test solutes were measured at each modifier concentration. The solutes were dissolved in $n$-hexane, except 2-HEMA, which was dissolved in dichloromethane. Column hold-up times were measured from the refractive index signal of hexane or from the dichloromethane peak. Capacity ratios were calculated from the peak maximum. The concentrations of the test solutes were approximately $10^{-3} \mathrm{~mol} / \mathrm{l}$. The injection volume was $1 \mu \mathrm{l}$.

\section{Table 1}

Relative number of adsorbing molecules according to eq. (9).

\begin{tabular}{ll} 
Modifier & $1 / \alpha$ \\
\hline Methanol & 1.0 \\
Ethanol & 0.38 \\
1-Propanol & 0.24 \\
2-Propanol & 0.12 \\
1-Butanol & 0.17 \\
2-Butanol & 0.10 \\
Isobutanol & 0.08 \\
tert-Butanol & 0.06 \\
THF & 0.13 \\
1,4-Dioxane & 0.08 \\
Acetone & 0.06 \\
Ethyl acetate & 0.01 \\
Benzene & - a) \\
Dichloromethane & -a) \\
Nitromethane & - a) \\
\hline
\end{tabular}

a) No detectable variation of retention with injected amount. 


\section{Results and Discussion}

\subsection{Relative Numbers of Adsorbing Molecules}

In Table 1, reciprocal $\alpha$ values are listed for various modifiers These values can be considered as an indication of the maximum numbers of modifier molecules that can adsorb on the surface. The value for methanol was normalized to 1. A low reciprocal $\alpha$ value is expected either for large molecules, which have no access to sterically hindered silanols, or for solutes with a low affinity towards silanol groups. Within the series of alcohols, Table 1 clearly shows a higher maximum surface coverage for smaller molecules. Most likely, this is caused by a better accessibility of active sites for the smaller molecules [2]. Branched molecules show lower maximum surface coverage in comparison with linear isomers

Of the other modifiers studied, benzene, dichloromethane, and nitromethane showed no measurable influence of the sample size on retention. This suggests that these components do not interact with the silanol groups on the surface under the experimental conditions. It appears that the interactions between the surface and the modifiers are primarily due to hydrogen-bonding (proton accepting) interactions. For example, benzene, the molecular size of which is similar to that of THF, shows no measurable adsorption. This is in agreement with experiments of Boudreau and Cooper [20], who classified silica as a proton-donating surface, which would consequently show interaction particularly with proton-accepting modifiers or solutes.

\subsection{Adsorption Isotherms}

Figure 2 shows the adsorption isotherm of THF on Chromspher octadecyl-modified silica. When the experimental points shown in Figure 2 were fitted to the linearized form of eq. (3), a close fit (straight line not shown) was observed over the entire concentration range, except from a slight deviation at low concentra. tions. According to Scott and Kucera [12], this could be caused by the presence of a small number of active sites with a higher activity than the remainder of the sites.

In additional experiments isotherms were measured for some commonly used modifiers. In Figure 3 , Langmuir isotherms are plotted which have been fitted through the experimental data points (not shown). The highest surface coverages were obtained for the smallest molecules. This is in agreement with the results described in the previous section. The concentration required to obtain a certain percentage of the maximum surface coverage is dependent on the modifier. From the adsorption isotherms, the concentrations of modifier that are required to obtain (almost) complete surface deactivation (e.g. 90 or 95\%) can be estimated. The surface coverage of, for example, ethanol increased sharply at modifier concentrations lower than (approximately) $0.1 \%$. At $0.4 \%$ the surface coverage and, hence, the surface deactivation, is close to its maximum. The main effect of increasing the ethanol concentration above $0.4 \%$, will be a modification of the mobile phase, because the stationaryphase coverage remains almost constant. Of the modifiers studied, 2-propanol required the lowest concentrations to obtain maximum surface coverage. In Table $\mathbf{2}$, the extrapolated maximum surface coverages and the concentrations of modifier in the mobile phase needed to reach $90 \%$ and $95 \%$ of the maximum coverage are given.

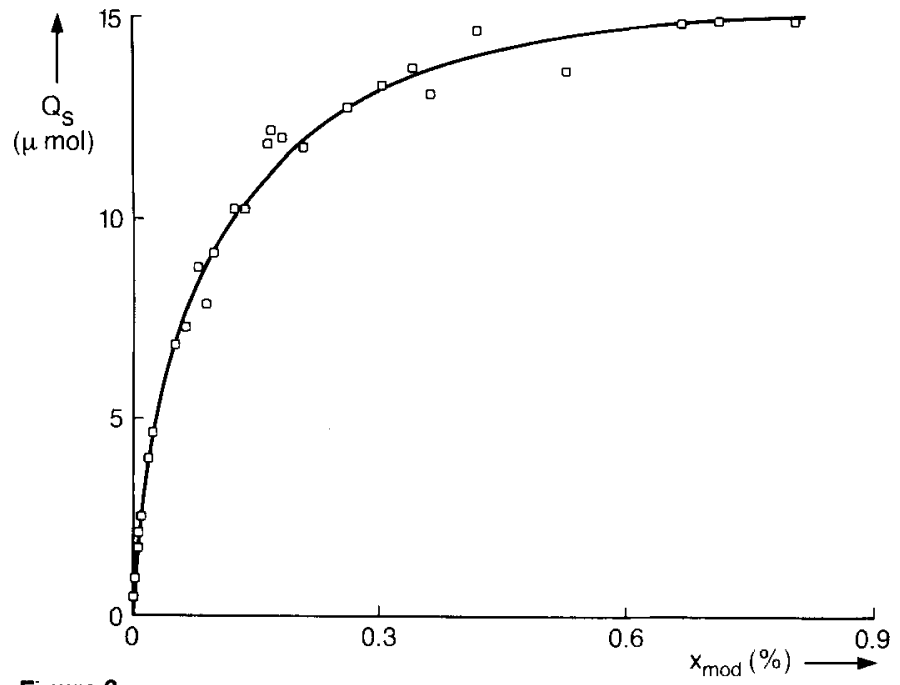

Figure 2

Adsorption isotherm of THF on octadecyl-modified silica from carbon dioxide with ca. $5 \%(\mathrm{v} / \mathrm{v})$ hexane. Column inlet pressure: 179 bar, outlet pressure: 162 bar. Temperature $45^{\circ} \mathrm{C}$.

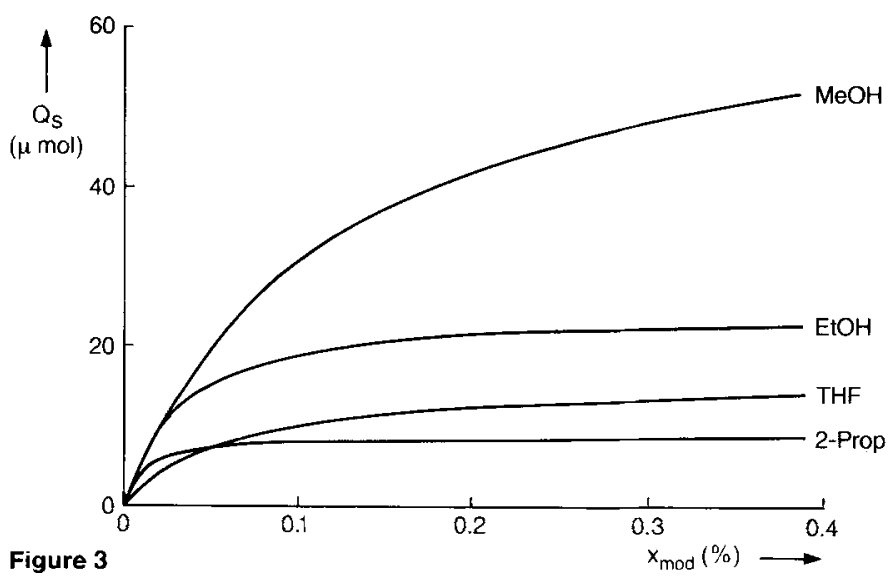

Fitted adsorption isotherms for various modifiers on octadecyl-modified silica from carbon dioxide with ca. $5 \%(v / v)$ hexane. Conditions as in Figure 2.

Table 2

Maximum surface coverages for the entire column and concentrations needed to reach $90 \%$ and $95 \%$ coverage.

\begin{tabular}{|c|c|c|c|c|}
\hline Modifier & Methanol & Ethanol & 2-Propanol & THF \\
\hline $\begin{array}{l}\text { Maximum coverage } \\
\text { ( } \mu \mathrm{mol})\end{array}$ & 68 & 25 & 8.6 & 16 \\
\hline $\begin{array}{l}90 \% \text { coverage } \\
\text { mol } \% \\
\text { vol } \% \text { a) } \\
\text { weight } \%\end{array}$ & $\begin{array}{l}1.1 \\
1.1 \\
0.79\end{array}$ & $\begin{array}{l}0.31 \\
0.39 \\
0.32\end{array}$ & $\begin{array}{l}0.10 \\
0.17 \\
0.13\end{array}$ & $\begin{array}{l}0.55 \\
0.97 \\
0.88\end{array}$ \\
\hline $\begin{array}{l}95 \% \text { coverage } \\
\text { mol } \% \\
\text { vol } \%{ }^{a)} \\
\text { weight } \%\end{array}$ & $\begin{array}{l}2.3 \\
2.2 \\
1.7\end{array}$ & $\begin{array}{l}0.66 \\
0.83 \\
0.68\end{array}$ & $\begin{array}{l}0.21 \\
0.35 \\
0.28\end{array}$ & $\begin{array}{l}1.2 \\
2.1 \\
1.9\end{array}$ \\
\hline
\end{tabular}

a) For the calculation of the volume percentages, the density of liquid $\mathrm{CO}_{2}$ was assumed to be $1.0 \mathrm{~g} / \mathrm{ml}$ under the conditions in the pump heads. 


\subsection{Effects of Modifiers on Retention}

In the introduction section, the effects of adding a modifier to the mobile phase were divided in a mobile-phase modification effect and a stationary-phase effect. The addition of modifiers was suggested to result in both a density effect and a physicochemical effect in the mobile phase. Stationary-phase deactivation was identified as a parameter of interest, mainly in packed-column SFC. To study the effects of the changing density of the mobile phase on the retention of solutes, hexane was used as a modifier. Due to its apolar nature, hexane was believed not to exhibit any interaction with silanol groups on the packing material, nor was it believed to show any specific interaction with solute molecules in the mobile phase. Hence, any effect of the addition of hexane on the retention of a solute was thought to be caused exclusively by changes in the mobile-phase density.

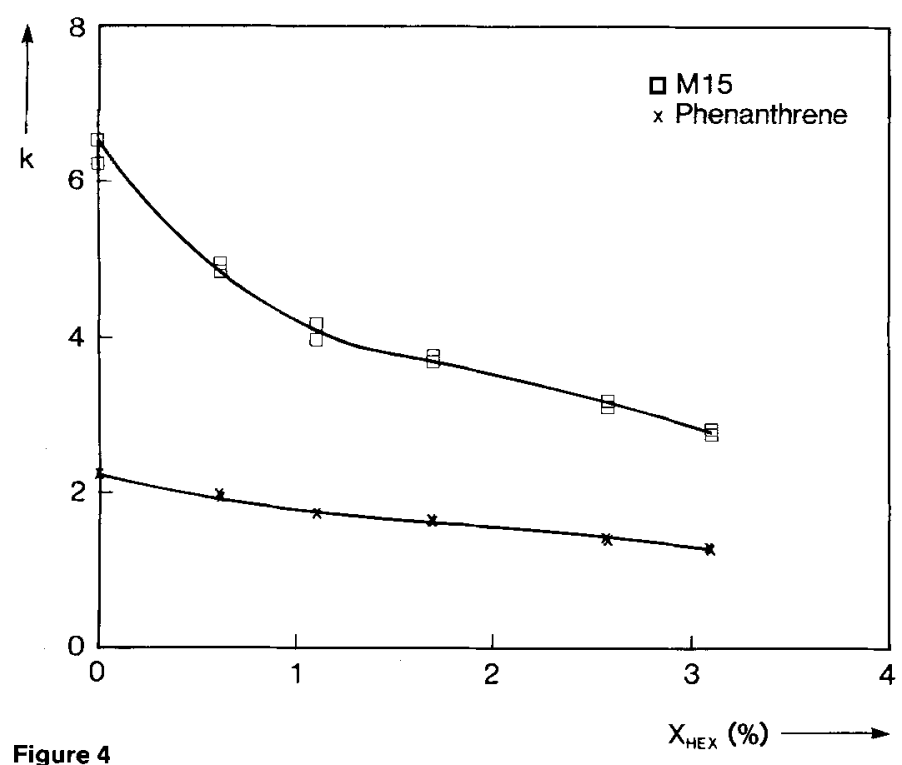

Variation of the observed capacity factors of phenanthrene and M15 with the concentration of hexane. Conditions as in Figure 2.

Figure 4 illustrates the effects of low percentages of hexane on the capacity factors of M15 and phenanthrene. The figure shows an appreciable influence of the hexane concentration on the retention of the solutes. If it is assumed that the effect of hexane on the capacity factors of the solutes is caused primarily by a density change, an approximately linear relationship is expected between the logarithm of the capacity factor and the mobilephase density. Such a linear relationship between ln $k$ and density is often observed with neat $\mathrm{CO}_{2}$, especially when only a narrow range of densities is considered. To verify the assumption that the effects of the hexane addition are caused by a density change of the mobile phase, linear regression was applied to graphs of $\ln k$ vs. density. The densities of the carbon dioxide/hexane mixtures were calculated using the Lee and Kesler equation [21]. The slopes of the regression lines of ln $k v s$. $\rho$ are given in Table 3 . These slopes are in good agreement with literature values measured with pure carbon dioxide. For example, Chester and Innis [22] measured a slope of $-11.0 \mathrm{ml} / \mathrm{g}$ for dodecane at $89^{\circ} \mathrm{C}$ on a 007 methyl-silicone column. Schoenmakers [23] calculated slopes of $-7.7 \mathrm{ml} / \mathrm{g}$ using a thermo-

\section{Table 3}

Slopes and correlation coefficients of the regression lines of In $k v s$. density. Column: Chromspher $C_{18}(150 \times 4.6 \mathrm{~mm}), 5-\mu \mathrm{m}$ particles. $P_{\text {in }}=179$ bar, $P_{\text {out }}=162$ bar.

\begin{tabular}{lllll}
\hline Solute & \multicolumn{2}{c}{$45^{\circ} \mathrm{C}$} & & \multicolumn{2}{c}{$55^{\circ} \mathrm{C}$} & \\
\hline & $\begin{array}{l}\text { Slope } \\
\mathrm{ml} / \mathrm{g}\end{array}$ & $\begin{array}{l}\text { Corr. } \\
\text { Coeff. }\end{array}$ & $\begin{array}{l}\text { Slope } \\
\mathrm{ml} / \mathrm{g}\end{array}$ & $\begin{array}{l}\text { Corr. } \\
\text { Coeff. }\end{array}$ \\
\hline M15 & -7.04 & 0.996 & -6.54 & 0.995 \\
Phenanthrene & -4.74 & 0.989 & -4.70 & 0.989 \\
\hline
\end{tabular}

dynamic model for SFC. The results seem to indicate that the effects of density on retention are comparable, regardless of whether the origin of the increased density is a pressure increase of pure carbon dioxide or the addition of a modifier to the mobile phase at constant pressure. This is in agreement with Martire's unified theory of chromatography [24], where the mobile phase is assumed to consist of a lattice of mobile phase molecules and unoccupied spaces. On adding hexane to the mobile phase or increasing the density, the fraction of occupied sites increases.

For polar modifiers, besides density, two additional effects on retention can be anticipated. For this type of modifier, both the stationary-phase deactivation effect and the occurrence of specific interactions between the modifier and the solute in the mobile phase might become important. Since the effects of small amounts of modifiers are much larger in packed-column SFC than in capillary SFC, it appears that the first mechanism is the predominant one. To study the effects of stationary-phase deactivation by the modifier on the retention behavior of the solutes, polar, hydrogen-bonding modifiers were added to the carbon dioxide. In contrast to the non-polar hexane, which is assumed not to interact with active sites, polar modifiers are selieved to reduce the number of active sites by preferential adsorption on silanol groups. Our method of preparing extremely low concentrations of modifiers by adding a total of $5 \%(\mathrm{v} / \mathrm{v})$ of hexane plus modifier leads to an approximately constant mobile phase density. Hence, density effects on retention are expected to be small.

Figure 5 illustrates the effects of low concentrations of THF on the capacity factor of 2-HEMA. A 30-fold decrease in retention was observed upon the addition of $1.1 \% \mathrm{THF}$ to the mobile phase. The upper line in the figure represents the fraction of sites not occupied by THF. This line was calculated from eq. (5) using experimentally obtained coefficients. The lower line gives the experimentally measured capacity factors of the test solute. A clear correlation is observed between the fraction of uncovered silanols and the retention of the solute. This indicates that the influence of the modifier on retention is primarily due to surface deactivation. For 2-HEMA, under the experimental conditions used, the contribution of the chemically bonded phase to the retention appeared to be negligible. Retention appeared to be almost exclusively determined by the interaction with unreacted silanol groups.

Figure 6 shows the results of similar experiments carried out with other test solutes. These solutes showed less drastic changes in retention. For example, for benzophenone the capacity factor was found to decrease from 1.5 with pure $\mathrm{CO}_{2}$, to 


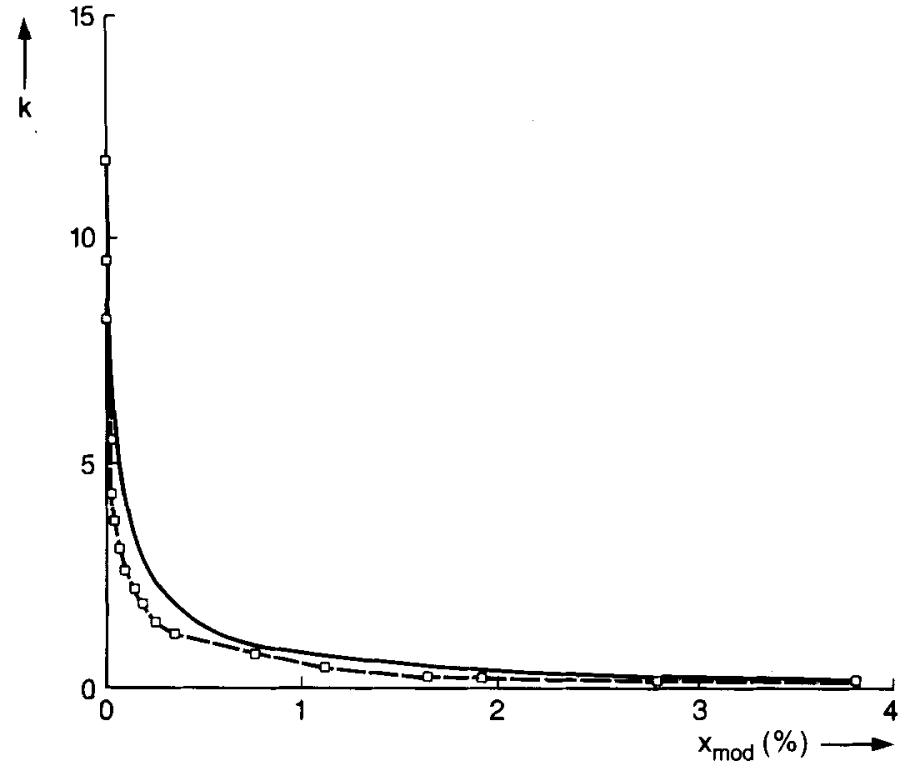

Figure 5

Normalized fraction of uncovered silanols (drawn line) and experimental variation of the observed capacity factor of 2-hydroxyethyl methacrylate (dashed line) with the modifier concentration. The drawn line was calculated from eq. (5). Modifier: THF. Conditions as in Figure 2.

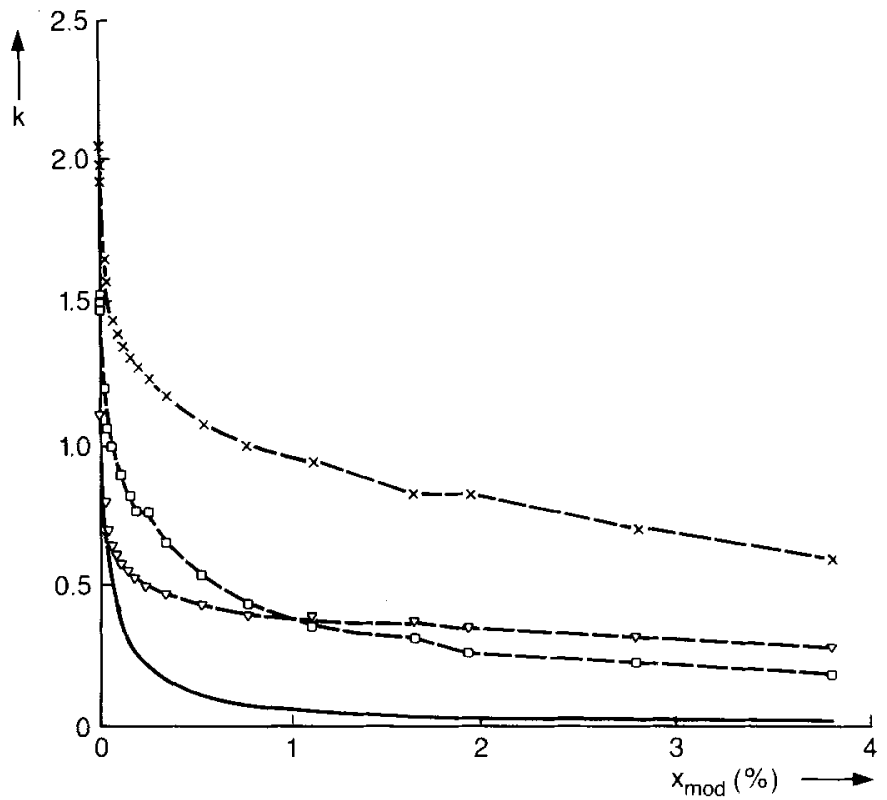

Figure 6

Variation of the observed capacity factors for $M 15(\times)$, benzophenone $(\nabla)$, and phenol $(\square)$ with the concentration of THF. The drawn line gives the calculated fraction of uncovered silanol groups [calculated according to eq. (5)]. Conditions as in Figure 2.

0.40 at $0.4 \%$ THF. Further increasing the modifier concentration up to $4 \%$ had no significant additional effect on retention Apparently, the surface deactivation was complete at a modifier concentration of $0.4 \%$. Beyond this concentration, only the con
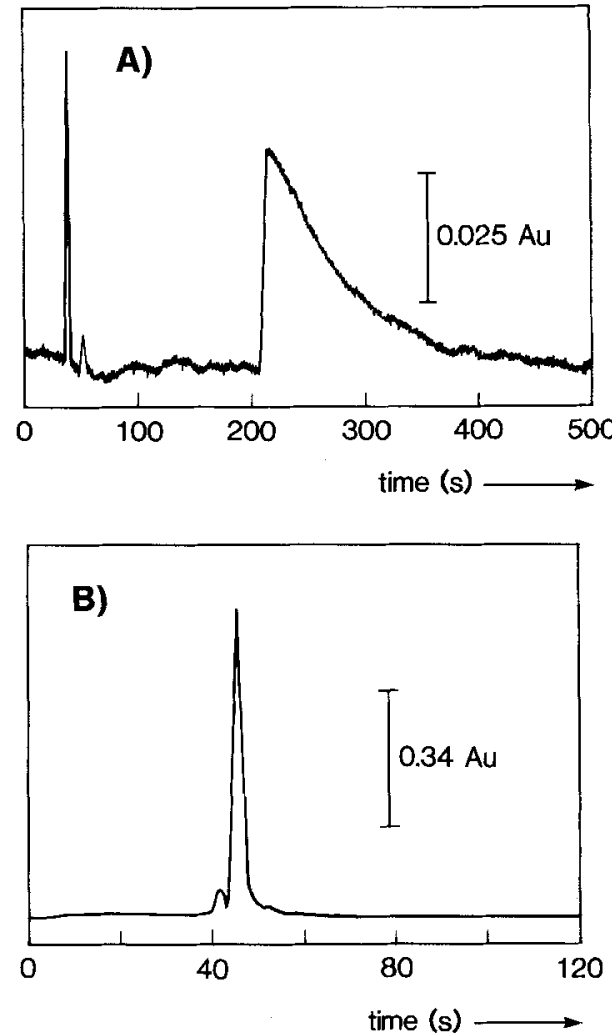

Figure 7

Modifier effect on the peak shape. Modifier: Ethanol. Solute: 2-HEMA. Modifier concentration: A: $0.013 \%$, B: 1.1\%. Conditions as in Figure 2.

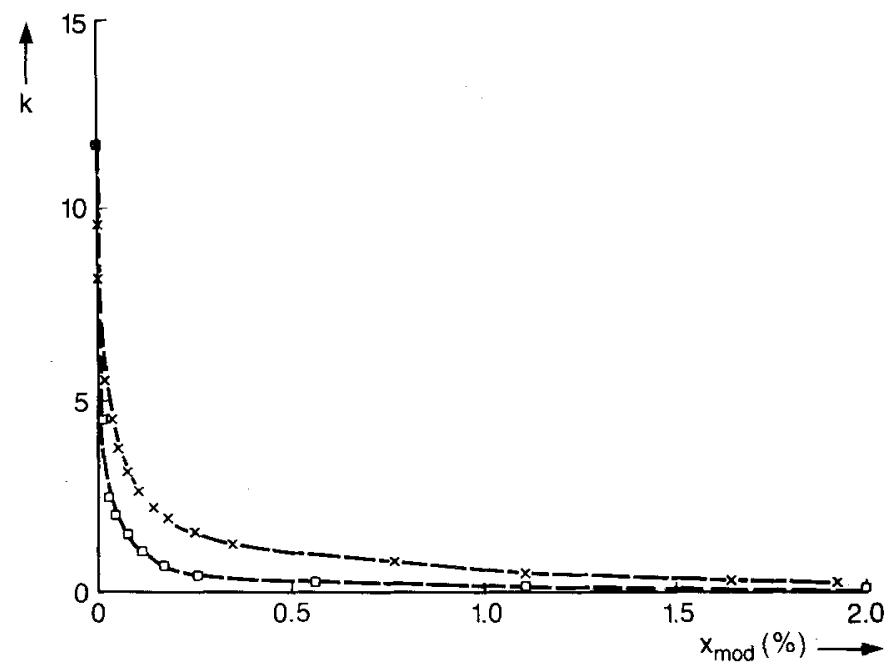

Figure 8

Variation of the observed capacity factor of 2-hydroxyethyl methacrylate with the concentration of THF (upper line) and ethanol (lower line). Conditions as in Fig. 2.

stant CBP contribution to overall retention remained. However, for phenol, the initial sharp decrease of retention was superimposed on a gradual retention decrease. Apparently, the assumption of a constant contribution from the chemically 
bonded phase is not valid for this component. Possibly, this is caused by a change in the density of the mobile phase on changing the ratio of hexane and THF added to the carbon dioxide. However, this effect is likely to be the same for all solutes. Another possibility is that specific interactions (i.e. hydrogen bonding) in the mobile phase become significant.

Figure 7 illustrates the effect of ethanol on the peak shape of 2-HEMA. Whereas the solute shows up as a broad, tailing peak at a modifier concentration of $0.013 \%$, a sharp, symmetrical peak is obtained at a modifier concentration of $1.1 \%$.

In Figure 8, the effects of two different modifiers on the retention of 2-HEMA are compared. From this figure, ethanol appears to be a better modifier than $\mathrm{THF}$, since retention is lowest with ethanol at all concentrations. This observation is in agreement with the results from the isotherm measurements, where a fixed degree of surface deactivation was obtained at lower concentrations for ethanol than for THF.

\section{Conclusions}

1) Low concentrations of modifiers can lead to considerable improvements in retention and peak shape of polar solutes on octadecyl-modified columns in packed-column SFC. The absolute magnitude of the retention decrease depends strongly on the nature of the solute

2) Adsorption isotherms of modifiers in packed-column SFC can be measured using the breakthrough or frontal-analysis method. The isotherms obtained show close fits to the Langmuir adsorption model. The maximum amount of modifier adsorbed on the surface strongly depends on the molecular size and structure. Hydrogen-bonding properties appear to be important.

3) Adsorption isotherms of modifiers can be used to estimate the concentrations required for obtaining maximum surface coverage

4) The capacity factors of polar solutes at different modifier con centrations were found to correlate well with the amount of modifier adsorbed on the surface. This suggests that the effects of low concentrations of modifier are primarily caused by stationary-phase deactivation.

5) The variation of the observed capacity factor with the modifier concentration can be described accurately by a mixed-retention model. In this model, silanol groups and chemically bonded groups contribute independently to overall retention.

6) The addition of a fluid modifier can result in a substantial increase in the mobile-phase density. The effect of this density increase on retention is comparable to the effect of a pressure-induced density increase with neatcarbon dioxide.

7) The influence of mobile-phase modification on the reduction of the retention was found to be small in comparison with the initial effects caused by stationary-phase deactivation.

\section{Acknowledgments}

The fruitful discussions with Louis Uunk as well as his technical assistance are gratefully acknowledged.

\section{References}

[1] J. M. Levy and W. M. Ritchey, J. Chromatogr. Sci. 24 (1986) 242

[2] A. L. Blilie and T. Greibrokk, Anal. Chem. 57 (1985) 2239.

[3] P. Mourier, P. Sassiat, M. Caude, and R. Rosset, J. Chromatogr 353 (1986) 61

[4] R. Board, D. MC.Manigill, H. Weaver, and D. Gere, Hewlett-Packard publication no 43-5953-1647, 1982

[5] J. M. Levy and W. M. Ritchey in: Proc. 6th Int. Symp. Capillary Chromatography, Riva del Garda, P. Sandra and W. Bertsch (eds.), Huethig, Heidelberg (1985) p. 925.

[6] S.M. Fields, K. E. Markides, and M. L. Lee, J. Chromatogr. 406 (1987) 223.

[7] C. R. Yonker and R. D. Smith, J. Chromatogr. 361 (1986) 25.

[8] C. R. Yonker, S. L. Frye, D. R. Kalkwarf, and R. D. Smith. J. Phys. Chem. 90 (1986) 3022.

[9] C. R. Yonker, T. A. Zwier, and M. F. Burke, J. Chromatogr 241 (1982) 257.

[10] S. R. Springston, P. David, S. Steger, and M. Novotny, Anal. Chem. 58 (1986) 257

[11] J. R. Conder, J. High Res. Chromatogr. and Chromatogr. Comm. 5 (1982) 341

[12] R. P. W. Scott and P. Kucera, J. Chromatogr. 149 (1978) 93

[13] J. A. Jonsson and L. Mathiasson, J. Chromatogr. 179 (1979) 1.

[14] C. H. Lochmüller and L. P. Mink, J. Chromatogr 409 (1987) 55.

[15] A. W. de Jong, J C. Kraak, H. Poppe, and F. Nooitgedacht, J. Chromatogr. $193(1980) 181$.

[16] J. Jacobson, J. Frenz, and C. Horváth, J. Chromatogr. 316 (1984) 53.

[17] P. J.Schoenmakers and F. C. C. J. G. Verhoeven, Trends Anal. Chem. 6 (1987) 20.

[18] P. J. Schoenmakers, L. G. M. Uunk, and P. K. de Bokx, J. Chromatogr 459 (1988) 201.

[19] J.F. K. Huber and R. G. Gerritse, J. Chromatogr. 58 (1971) 137

[20] S. P. Boudreau and W. T. Cooper, Anal. Chem. 59 (1987) 353

[21] B. I. Lee and M. G. Kesler, AIChE J. 21 (1975) 510

[22] T. L. Chester and D. P. Innis, J. High Res. Chromatogr. and Chromatogr. Comm. 8 (1985) 561.

[23] P. J. Schoenmakers, J. Chromatogr. 315 (1984) 1

[24] D. E. Martire, J. Liq. Chromatogr. 10 (1987) 1569.

Ms received: May 25, 1989 Accepted: August 1, 1989 